aus weiter Ferne den mir bekannten schrillen Ton: tick, tick, tick etc., während ein Syrrhaptes im schnellen Fluge sich mir näherte.

Wenn nun auch dieser Vogel bereits auf hundert Schritt seitwärts abschwenkte, in dieser Entfernung mich ein Mal umkreiste, und dann in derselben Richtung, woher er gekommen, forteilte, so konnte ich das Thier doch genau erkennen und namentlich deutlich den hellen Bauch und das schwarze Brustschild sehen. Diesmal war der Flug übrigens nicht niedrig, sondern gewiss hundert Fuss hoch. Derselbe war so pfeilschnell und die Luft durchschneidend, dass man deutlich einen pfeifend-schwirrenden 'Ton der Flügel hören konnte, während er, so lange ich ihn sehen konnte, das Geschrei tick-tick- etc. von Zeit zu Zeit in ziemlich gleichmässigén Pausen hören liess. -

Nachmittags suchte ich die ganze Barther Gemarkung vergebens ab. Einer der hiesigen Jagdpächter will noch am 23. c. zwei Steppenhühner gesehen haben; wie auch ein Gutsbesitzer um dieselbe Zeit einen Flug auf seinem zwischen Stralsund und Greifswald belegenen Gute beinerlkt haben will.

Damit schliesse ich meine Syrrhaptes-Beobachtungen, und erwähne nur noch, dass ich auch fernerhin den Vogelsang im Auge behalten werde, während ich andererseits hoffe, an meinem lieben kleinen Stubengenossen, der sich mit seinem amputirten Flügel äusserst wohl befindet, Beobachtungen zu machen, welche ich seiner Zeit dem Journal für Ornithologie einzuschicken gedenke.

Barth, den 31. October 1863.

\title{
Nachrichten.
}

\section{Nachruf. (A. Goffin.)} klagen!

Die Ornithologie hat den Verlust eines ihrer ergebensten Jünger zu be-

Am 15. d. M. verschied zu Mastricht an einem Brustleiden, dessen unerwartet trauriges Ende er selbst nicht geahndet, Herr A. Go ffin, 1. Lientenant im 4. Linien-Infanterie-Regiment, in dem blühenden Alter von 24 Jahren.

Von früher Jugend an mit einer seltenen Liebe für die Naturwissenschaften beseelt, wählte er jedoch bald die Ornithologie zu seinem Hanptstudium und hier war es wieder besonders die Ornis Westafrika's, die in ihm einen eben so gründlichen Kenner, als zukünftigen Durchforscher verloren hat. Durchdrungen von der Idee, dort selbst seine Thätigkeit bald entfalten zu können, 
war er fast 2 Jahre mit eisernem Fleiss besehäftigt, die reichen Schätze des hiesigen Museums durchzarbeiten. Wie sehr er jedoch anch in anderer Hinsicht den Namen eines Ornithologen verdiente, beweisst die in dem „Museum d'Histoire naturelle des Pays-bas" gegebene Monographie der Buccones, eine Arbeit, durch deren Gründlichkeit er sich gewiss in den weitesten wissensehaftlichen Kreisen ein gutes Andenken verschafft haben muss.

Leider war es sein erstes und letztes literarisches Product, welches ihm vergönnt war der Oeffentlichkeit zu übergeben.

Wohl konnte man mit Recht die glänzendsten Resultate erwarten von einem solchen in voller Manneskraft stehenden Forscher, der ausser seinem ganz besonderen Eifer für die Sache selbst, das Schwierige der sich gestellten Aufgabe vollkommen zu würdigen wusste. Er, der jede ornithologische Erscheinung zu deuten verstand, würde ohne $Z$ weifel durch seine Untersuchungen über viele fragliche Punkte das Licht verbreitet haben, welches die Ornis jener Gegenden, der es bisher so ganz an der Durchforschung von wirklichen Fachmännern gebricht, so nothwendig bedarf.

Leiden, im October 1863.

Otto Finsch.

\section{An die Tedaction eingegangene Schriften:}

(Siehe Juli-Heft, s. 320.)

485. A. J. Malmgren. Anteckningar till Spetsbergens Fogel-Fauna. (Aus Oefvers. af K. Vet.-Akad. Förh. 1863, No. 2.) - Vom Verfasser.

486. Jahresbericht der naturforschenden Gesellschaft Graubündens. Neue Folge. VIII. Jahrg. (Vereinsjahr 1861-62.) Chur 1863. - Von der Gesellschaft.

487. Constitution and By-Laws of the Boston Society of Natural History. 1855. Von der Gesellschaft.

488. Boston Journal of Natural History, containing Papers and Communications read before de Society of Nat. History. Vol. VII, No. 1-3. Boston 1859-1862. - Von Derselben.

489. Proceedings of the Boston Society of Natural History. Vol. IX, pag. 1-176. (April 1862 bis Febr. 1863.) - Von Derselben.

490. Otto Finsch. Naamlijst der in de Diergaarde levende Papegoaijen ten Dienste der Bezoekers van den tuin ingerigt. - Vom Verfasser.

491. Geo. N. Lawrence. Catalogue of a Collection of Birds made in NewGranada, by James Mc. Leannan, with Notes and Descriptions of NewSpecies. Part. IV. (From. Ann. of Lyceum of Nat. Hist. New-York Vol. VIII. May 1863.) -- Vom Verfasser.

492. Naturaliensammlung. Artikel aus dem Haus- und Familien-Lexicon Bd. V. S. $661-666$, von L. Martin. - Vom Verfasser.

493. Rules for Zoological Nomenclature by the late Hugh E. Strickland. Authorised by Section D. of British Association at Manchester, 1842. Reprinted by Requisition of Section D. at Newcastle, 1863. Edinburgh. Printed by Neill and Co. 1863.

404. The Ib is. A Magazine of General Ornithology. Edited by Ph.L.Sclater. Vol. V. No. 20. October 1863. - Von der British Ornithologist's Union.

Berlin, Druck von Kornegg's Buchdruekerel. 